\title{
CELPE-BRAS: confecção de material didático
}

\author{
Anelise Fonseca Dutra, \\ Universidade Federal de Ouro Preto \\ Sílvia Penna \\ Universidade Federal de Ouro Preto
}

\begin{abstract}
Resumo
O CELPE-BRAS, Certificado de Proficiência em Língua Portuguesa para Estrangeiros, é conferido aos estrangeiros com desempenho satisfatório em português. A Universidade Federal de Ouro Preto (UFOP) tem parcerias com instituições estrangeiras, o que suscitou numa crescente demanda por parte de estudantes estrangeiros (de um curso de preparação para este teste). Entretanto, há uma lacuna na preparação que UFOP oferece aos interessados em prestar o exame. Este projeto pretendeu contribuir na elaboração de material adequado para a preparação do aluno em um curso de Português voltado para o CELPE-Bras, pautado pela abordagem comunicativa (Brown, 2001; Almeida Filho, 1993; Widdowson, 1978; entre outros).
\end{abstract}

Palavras Chave: Português para estrangeiros, confecção de material didático, sequência didática.

\begin{abstract}
The Certificate of Proficiency in Portuguese for Foreigners (Celpe-Bras) is granted by MEC to foreigners with a satisfactory performance in the Portuguese language. Although the Federal University of Ouro Preto has been receiving an increasing number of foreign students and professors, there is not an adequate course to prepare students to take the exam. This project was conducted in order to develop materials with several didactic sequences to help students become prepared to obtain this certificate. The material was developed following the communicative approach proposed by authors like Brown (2001), Almeida Filho (1993), and Widdowson (1978), among others. Keywords: Portuguese for foreigners, materials development, didactic sequence
\end{abstract}

\section{INTRODUÇÃO}

O interesse pela língua portuguesa por parte de estrangeiros tem crescido sistematicamente, o que pode ser comprovado pela grande quantidade de cursos de ensino de português como língua estrangeira oferecidos no Brasil. Também no exterior, há um aumento da procura por parte de estudantes e por centros e instituições 
responsáveis pela divulgação da língua e cultura portuguesa e brasileira. Podemos citar, entre eles, os CEBs (Centros de Estudos Brasileiros) e o Instituto Camões. Outro ponto que confirma o crescimento do interesse pela língua portuguesa é demonstrado pelo aumento da procura por certificação de proficiência na língua portuguesa (exemplos: CILPE - Certificado Internacional de Língua Portuguesa e o CELPEBRAS - Certificado de Proficiência em Língua Portuguesa para Estrangeiros), para que o estrangeiro possa trabalhar no Brasil ou validar seu diploma.

O Celpe-Bras, Certificado de Proficiência em Língua Portuguesa para Estrangeiros, é conferido aos estrangeiros com desempenho satisfatório em teste padronizado de português, desenvolvido pelo Ministério da Educação. O exame é aplicado no Brasil e em outros países com o apoio do Ministério das Relações Exteriores. Internacionalmente, o Celpe-Bras é aceito em firmas e instituições de ensino como comprovação de competência na língua portuguesa e, no Brasil, é exigido pelas universidades para ingresso em cursos de graduação e em programas de pósgraduação. Outorgado pelo MEC, o Celpe-Bras é o único certificado brasileiro de proficiência em português como língua estrangeira reconhecido oficialmente.

A Universidade Federal de Ouro Preto tem assinado (e mantido) acordos com diversas instituições estrangeiras, e tem havido uma crescente demanda por parte de estudantes estrangeiros de graduação e pós-graduação para realizar estudos nessa universidade. Além disso, a instituição recebe com frequência professores visitantes estrangeiros para atuar temporariamente em áreas de ensino e pesquisa.

Entretanto, apesar de ser uma exigência, havia uma lacuna na Universidade Federal de Ouro Preto em oferecer a esses interessados uma preparação adequada para a realização do exame, que ocorre em quatro níveis: intermediário, intermediário superior, avançado e avançado superior. O Departamento de Letras, por meio do Centro de Extensão, procurou oferecer possibilidades para os interessados estudarem a língua portuguesa, com o intuito de se aprimorarem e, consequentemente, se prepararem para obter o Certificado exigido pelo MEC.

O Departamento de Letras, especificamente, nas disciplinas voltadas para a Linguística Aplicada, oferece aos seus alunos uma formação adequada para que atuem como professores de português como língua materna e/ou como professores de inglês como língua estrangeira. As disciplinas relacionadas à Linguística Aplicada ao Ensino 
de Línguas Estrangeiras são voltadas para a formação de profissionais que atuam como professores de inglês como língua estrangeira no contexto sociocultural brasileiro. Parte desse conhecimento pode também ser aplicada ao ensino de PLE (Português como Língua Estrangeira). No entanto, não havia uma preparação específica para a formação de um profissional que trabalhasse com a língua portuguesa para o ensino de estrangeiros. Essa área de atuação exige uma formação específica que demanda conhecimento da língua portuguesa a partir de um ponto de vista de 'estranhamento', ou seja, de percepção de suas regras, exceções, nuances de pronúncia, estrutura e uso interacional que permita explicitar seu funcionamento a estrangeiros, e exige também uma consciência intercultural que facilite o trabalho com alunos de outras culturas.

Assim, o projeto desenvolvido no Departamento de Letras da UFOP foi igualmente importante por oferecer a possibilidade de ampliação do campo de trabalho (ensino e pesquisa) de seus professores e alunos, focalizando também o português como língua estrangeira. Isso colabora na formação de alunos do curso de Letras, pois os incluiu na prática e na reflexão pedagógicas, e os capacita a uma melhor compreensão dos aspectos envolvidos no processo de ensino/aprendizagem de línguas estrangeiras.

\section{OBJETIVOS E METODOLOGIA}

O projeto desenvolvido teve como primeiro objetivo o estudo e análise do material utilizado nos exames do Celpe-Bras (Certificado de Proficiência em Língua Portuguesa para Estrangeiros). Como segundo objetivo, pretendeu contribuir na elaboração de material adequado para a preparação do aluno em um curso de Português para Estrangeiros, oferecido pelo Centro de Extensão do Instituto de Ciências Humanas e Sociais. O objetivo geral foi consolidar a área de ensino e pesquisa em Português para Estrangeiros junto ao Departamento de Letras da UFOP, possibilitando aos alunos desse curso uma opção a mais para sua atuação profissional no desenvolvimento de atividades em Linguística Aplicada ao Ensino de Línguas Estrangeiras, focalizando no planejamento e execução de cursos, formação docente, elaboração de materiais didáticos e publicações teóricas voltadas para a área. 


\section{ABORDAGENS TEÓRICAS}

Almeida Filho e Lombello (1997) ressaltam a importância de um ensino de línguas, mais especificamente de português para estrangeiros, que seja adequado às necessidades dos alunos, de modo que estes sejam o centro do processo de ensino/aprendizagem. Essa opinião é também compartilhada por outros autores da área, os quais destacam a importância de formar indivíduos capazes de utilizar a língua-alvo em situações reais de comunicação. Entretanto, percebe-se que o ensino da língua portuguesa para estrangeiros ainda tem acontecido sob uma visão estereotipada de linguagem que prioriza a transmissão de conteúdos irrelevantes para o aluno, o que pode ser explicado pela falta de materiais flexíveis e pela dificuldade ainda encontrada pelos profissionais da área no que tange à “(...) falta de critério para a seleção de métodos próprios" (FILHO \& LOMBELLO, 1997, p. 21).

O exame Celpe-Bras surgiu para atender aos programas de imigração de estrangeiros no Brasil, visando certificar a proficiência dessas pessoas que precisam se integrar ao contexto brasileiro ou utilizar a língua portuguesa no exterior (SCARAMUCCI, 2008, p. 179). Entretanto, a criação do Celpe-Bras também contribuiu para direcionar o ensino/aprendizagem de Português como Língua Estrangeira, visto que este exige do candidato uma competência comunicativa que o possibilite atuar nos diversos contextos de comunicação. Assim, para cumprir o seu papel, o Celpe-Bras baseia-se nos princípios da Abordagem Comunicativa, preocupando-se com a língua enquanto uso:

Uma avaliação comunicativa, por sua vez, é aquela centrada no desenvolvimento de uma habilidade de expressão ou de uma competência de uso. [...] As principais características desse exame são: ênfase na comunicação/interação; [...] conteúdos autênticos ou contextualizados (SCARAMUCCI, 1999, p. 108).

Os objetivos e os conteúdos do Celpe-Bras são definidos de acordo com as necessidades dos candidatos no que diz respeito ao uso da língua-alvo, ou seja, é avaliada a competência comunicativa do estrangeiro apresentada na avaliação, e essa competência deve permitir que o estrangeiro possa atuar em situações reais de comunicação no dia-a-dia, como produzir e receber os variados textos orais e escritos, sabendo adequar a linguagem aos diversos contextos de comunicação: "Ser um usuário competente, nessa visão, pressupõe saber usar a língua em contextos variados 
adequados às situações socioculturais e aos seus interlocutores.” (SCARAMUCCI, 1993, p.155).

Por acreditar nos efeitos positivos que o Celpe-Bras pode acarretar aos candidatos estrangeiros que se submeterem a esse exame, o critério adotado para elaboração do material didático produzido pela Universidade Federal de Ouro Preto baseia-se no conceito de efeito retroativo da avaliação no ensino de línguas. Como efeito retroativo, pode-se entender o impacto que um exame exerce sobre o processo de ensino/aprendizagem. Este impacto pode ser considerado positivo ou negativo. No caso específico de um exame da natureza do Celpe-Bras, acreditamos que esse efeito seja positivo no sentido em que ele exige do professor de PLE a adoção de uma prática pedagógica e de materiais didáticos que sejam coerentes com as suas exigências: "É muito mais provável ocorrer um ensino de línguas comunicativo quando a avaliação também é comunicativa” (SCARAMUCI, 1995, p. 77). Assim, baseando-se nessa premissa, a produção do material didático deste projeto de pesquisa pretendeu maximizar as chances de um efeito retroativo benéfico. Dessa forma, as atividades foram baseadas nos princípios da Abordagem Comunicativa (dentro de uma visão sociointeracional de ensino de línguas), da transversalidade e no trabalho com os gêneros textuais.

\section{A abordagem comunicativa}

A abordagem comunicativa surgiu na década de 70 como resposta à insatisfação com as abordagens tradicionais do ensino de línguas estrangeiras (MATTOS \& VALÉRIO, 2010). A proposta de um ensino comunicativo pretendia revolucionar o ensino de línguas a partir do entendimento da língua como meio de interpretação, expressão e negociação de significados. Desse modo, a aprendizagem de uma língua estrangeira não deixaria de ser centrada no conhecimento e memorização de regras gramaticais, mas estaria focada na capacidade de se fazer uso dessas regras em determinados fins comunicativos, sendo a língua entendida como instrumento de socialização, e a comunicação não apenas como objetivo da aprendizagem da línguaalvo, mas também como veículo para o seu ensino. Para que essa abordagem pudesse cumprir o seu papel, deu-se uma ênfase na centralidade do aluno no processo de 
ensino/aprendizagem, bem como em suas necessidades e interesses, de modo que este pudesse exercer um papel ativo em sala de aula. Além disso, o direcionamento das atividades passou a levar em conta a bagagem cultural dos indivíduos, pois, para o ensino comunicativo, o conhecimento prévio trazido pelos aprendizes viabiliza e contribui para o processo de aprendizagem. Dessa forma, a construção do conhecimento acontece a partir daquilo que o aluno traz consigo. Segundo Mattos e Valério (2010), outra característica dessa abordagem diz respeito ao desenvolvimento da consciência intercultural, através da qual o indivíduo conhece e compreende as diferenças existentes entre a sua cultura e a cultura da língua alvo.

Neste projeto, as atividades propostas para a preparação dos alunos para o exame Celpe-Bras visam alcançar o objetivo principal dessa abordagem, que é a formação de indivíduos conscientes e aptos para atuarem no mundo como cidadãos através da língua que está sendo aprendida.

\section{Os gêneros textuais}

O manual do candidato do exame Celpe-Bras afirma que este é um exame de natureza comunicativa. Em outras palavras, é um exame que não busca aferir conhecimentos a respeito da língua por meio de questões sobre a gramática e o vocabulário, mas sim a capacidade de uso dessa língua.

A competência do candidato é, portanto, avaliada pelo seu desempenho em tarefas que se assemelham a situações que possam ocorrer na vida real. Com base em uma visão da linguagem como uma ação conjunta de participantes com um propósito social, e considerando língua e cultura como indissociáveis, o conceito de proficiência que fundamenta o exame consiste no uso adequado da língua para desempenhar ações no mundo (Manual do candidato, 2006, p. 3). Nesse sentido, faz-se necessário o foco em gêneros textuais atuais que lidam com situações do cotidiano tanto em tarefas de produção como de compreensão oral e escrita.

Por gêneros textuais entende-se "textos materializados que encontramos em nossa vida diária e que apresentam características sócio comunicativas definidas por conteúdos, propriedades funcionais, estilo e composição característica" (MARCUSCHI, 2006, p. 22). Preparar o indivíduo para agir no mundo como cidadão significa prepará-lo 
para reconhecer, produzir e receber os variados gêneros textuais (orais e escritos), para que ele seja capaz de se comportar adequadamente nos diversos contextos da línguaalvo, tais como: se comportar em uma entrevista de trabalho, expressar sua opinião diante de uma informação, reclamar por alguma coisa, saber quando e como utilizar a linguagem formal ou informal etc. $O$ trabalho com os gêneros textuais está estritamente relacionado ao conceito de autenticidade definido por NUNAN (1999, p. 27) como "amostras de língua oral ou escrita que não tenham sido escritos especificamente com o propósito de se ensinar uma língua”. É fundamental a utilização de textos reais para informar ao aluno sobre a realização discursiva de diversas situações da língua-alvo, de modo que ele perceba as características e especificidades de um texto, para que seja capaz de reconhecê-lo em um contexto fora da sala de aula. Assim, ele captará as informações naturalmente ao ler ou escutar textos de diferentes gêneros e propósitos comunicativos, o que lhe dará maior autonomia, funcionando como uma forma de facilitar e acelerar o seu processo de aprendizagem.

\section{Os temas transversais}

O ensino de uma língua estrangeira abre espaço para tratar de questões que vão além dos aspectos linguísticos e culturais de um determinado idioma. Ele oferece uma grande oportunidade para focalizar a relação entre linguagem e sociedade, isto é, focalizar questões que envolvem o mundo social no qual o aprendiz está inserido. Assim, os temas transversais, que têm um foco claro em questões de interesse social, podem ser facilmente trazidos para a sala de aula via Língua Estrangeira. Os Parâmetros Curriculares de Ensino de Línguas Estrangeiras (PCNs) apontam os temas transversais como fundamentais para uma análise comparativa de como questões particulares são tratadas no Brasil e nos países (no nosso caso específico) estrangeiros de onde vêm nossos alunos. Esses temas tratam de questões sociais que estão relacionadas com a proposta da cidadania no ensino de línguas estrangeiras:

o respeito à ética nas relações cotidianas, no trabalho, e no meio político brasileiro; a preocupação com a saúde; a garantia de que todo cidadão brasileiro tenha direito ao trabalho; a consciência dos perigos de uma sociedade que privilegia o consumo em detrimento das relações entre as pessoas; o respeito aos direitos humanos (aqui incluídos os culturais e os lingüísticos); a preservação do meio ambiente; a pe 
rcepção do corpo como fonte de prazer; a consciência da pluralidade de expressão da sexualidade humana; a mudança no papel que a mulher desempenha na sociedade; a organização política das minorias étnicas por exemplo, os maoris na Nova Zelândia, os quéchuas no Peru, os argelinos na França, os ianomâmis no Brasil e na Venezuela - e não-étnicas — por exemplo, idosos, portadores de necessidades especiais, homossexuais, falantes de uma variedade não hegemônica (BRASIL, 1997, p. 44)

Se os temas transversais são fundamentais no ensino de uma língua estrangeira, o ensino de português como língua estrangeira (PLE) não pode se diferenciar e, nesse sentido, surge a necessidade de propostas didáticas que incorporem essa tendência e possam viabilizar um ensino voltado para a reflexão sobre as questões de interesse social e sobre os diversos aspectos que compõem o exercício da cidadania, contribuindo para a conscientização de seu papel no mundo enquanto cidadão. Nosso objetivo na confecção de materiais didáticos na preparação para o CELPE-Bras é focar nos temas transversais como uma diretriz em relação aos assuntos a serem estudados e discutidos nas aulas de PLE.

\section{RESULTADOS}

Depois de feita a leitura e o estudo de material teórico de ensino e aprendizagem de línguas estrangeiras, mais especificamente sobre o português como língua estrangeira, passamos para o desenvolvimento da segunda etapa da pesquisa, que foi a análise dos exames aplicados pelo Celpe-Bras e o levantamento dos critérios adotados pelos seus elaboradores.

Como citado anteriormente, o exame leva em consideração na sua confecção a abordagem comunicativa associada a uma visão sociointeracional de ensino de línguas, o uso de gêneros textuais e os temas transversais. Assim, em um segundo momento, vários textos e livros da área de ensino e aprendizagem de línguas que visavam os temas citados foram estudados e discutidos entre as autoras deste artigo e uma bolsista de iniciação científica.

Em uma etapa subsequente, foram elaboradas atividades para serem aplicadas em um curso preparatório para o Celpe-Bras. Essas atividades visam o desenvolvimento da competência comunicativa dos alunos, tendo como referencial direcionador as necessidades e interesses específicos, cujos focos são os aspectos contextuais exigidos para a comprovação da competência comunicativa. Foram 
utilizados estudos da estrutura da língua portuguesa que servem como suportes para a comunicação, além dos aspectos culturais da vida brasileira e da cultura interacional. Esses aspectos foram explorados de maneira a permitir um processo de formação intercultural que facilite a adaptação dos estudantes ao modo de viver de nossa cultura, e os preparem para a compreensão e a realização de um exame que abrange bem mais que aspectos linguísticos, mas igualmente o uso da língua nas comunicações do dia-adia e no ambiente acadêmico.

Foram elaboradas sequências didáticas ${ }^{1}$ sobre os seguintes temas: saúde, educação e meio ambiente. Vamos focar a sequência sobre saúde como exemplo para este artigo (ver anexo). O primeiro passo desta sequência é fazer um levantamento do conhecimento prévio que os alunos têm das partes do corpo e seus respectivos nomes em português. É importante citar que todas as fases da sequência apresentam atividades que aproximam o conhecimento da realidade do aluno, permitindo a todo momento uma comparação entre sua realidade e aquela vivenciada no Brasil. Em seguida, por meio de atividades diferenciadas, é apresentado o vocabulário que o aprendiz necessita tanto na vida real enquanto residente no Brasil, como para o desenvolvimento do restante da sequência. Foram feitas atividades de compreensão e produção oral e escrita, todas utilizando material autêntico, isto é, material que foi produzido por brasileiros para ser usado por brasileiros e não voltados para a sala de aula de língua estrangeira. As atividades apresentam questões antes, durante e após a sua realização. O objetivo das questões que precedem a atividade de compreensão oral e escrita é fazer um levantamento prévio do conhecimento do aluno, motivá-lo e guiálo para o trabalho a ser feito em seguida. As questões quem seguem exploram o texto em diferentes níveis de compreensão, partindo do superficial em que se testa a decodificação da língua, passando por um aprofundamento maior em que se discutem duplo sentido, entrelinhas, objetivos do autor etc, chegando a questões pós-texto em que são feitas discussões voltadas para a realidade (cultura) dos envolvidos no processo (professor e alunos). Várias destas atividades foram elaboradas para serem feitas em duplas ou em pequenos grupos. A interação é fator importante no processo de ensino-aprendizagem de uma língua e é igualmente exigida no exame. 
Como mencionado anteriormente, todas essas atividades são pautadas em gêneros textuais. Uma das atividades de leitura e compreensão oral apresenta uma campanha publicitária contra a dengue por meio de um cartaz e de uma propaganda no rádio. Como atividade de produção escrita, é pedido aos alunos que produzam igualmente uma campanha publicitária (pode ser um cartaz ou uma versão de spot de rádio). Para isto eles terão que utilizar todo o conhecimento adquirido ao logo da sequência didática, isto é, o conhecimento do assunto, assim como o vocabulário e a estrutura linguística geralmente associada a este gênero, o imperativo.

Todo o material produzido está sendo utilizado nas aulas de Português como Língua Estrangeira do Centro de Extensão do Instituto de Ciências Humanas e Sociais da Universidade Federal de Ouro Preto. Ele vem tendo boa aceitação entre os alunos e professores e tem suscitado discussões bem interessantes sobre a cultura brasileira e a cultura dos alunos. Até o momento, não tivemos alunos inscritos para o Celpe-Bras. No entanto, fizemos alguns testes, simulados e os alunos têm obtido um bom desempenho nas várias habilidades testadas.

\section{REFERÊNCIAS}

ALMEIDA FILHO, J.C.P. Língua além de cultura ou além de cultura, língua? Aspectos do ensino na interculturalidade. In: CUNHA, M. J. C.; SANTOS, P. (org.) Tópicos em Português Língua Estrangeira. Brasília: UnB, 2002.

ALMEIDA FILHO, J. C. P. Dimensões comunicativas no ensino de línguas. Campinas: Pontes, 1993.

ALMEIDA FILHO, J.C.P. \& L.C. (orgs.) O ensino de português para estrangeiros: Pressupostos para o planejamento de cursos e elaboração de materiais. Campinas, SP: Pontes 1989.

BIZON, A.C.C. Características da interação em contexto de ensino regular e em contexto interdisciplinar de português língua estrangeira: um estudo comparativo. Campinas, Unicamp, Dissertação de Mestrado, 1993.

CUNHA, M. J. C.; SANTOS P. Perspectivas contemporâneas na Formação de Professores de Português Língua Estrangeira. In: CUNHA, M. J. C.; SANTOS, P. (org.) Tópicos em Português Língua Estrangeira. Brasília: UnB, 2002.

DELL'ISOLA, R. L. P. Em busca da formação continuada do professor de português como LE: alguns parâmetros. In: JÚDICE, N. Ensino da língua e da cultura do Brasil para

Estrangeiros. 
Niterói: Intertexto, 2005. P.9-30.

DUTRA, A. F. O Processo Reflexivo-Colaborativo na Formação Inicial de Professores de Português Língua Estrangeira. Tese de Doutorado. UFMG - Belo Horizonte, 2010.

ELLIS, R. The study of second language acquisition. Oxford: Oxford University Press, 1994.

GIMENEZ, T.; FURTOSO, V. B. Formação de professores de portugués para falantes de outras línguas: alguns apontamentos iniciais. In: In: CUNHA, M. J. C.; SANTOS, P. (org.) Tópicos em Português Língua Estrangeira. Brasília: UnB, 2002.

JÚDICE, N. et al. O ensino de português para estrangeiros. Niterói: Edit. da UFF, 1996.

LITTLEWOOD, W. Communicative language teaching. Cambridge: Cambridge University Press, 1995.

MAGALHÃES, M. C. C. A linguagem na formação de professores como profissionais reflexivos e críticos. In: MAGALHÃES, M. C. C. (Org.) A formação do professor como um profissional crítico. Linguagem e Reflexão. Campinas: Mercado de Letras, 2004.

SCARAMUCCI, M. V. R. Efeito retroativo da avaliação no ensino/aprendizagem de línguas: o estado da arte. Trab. Ling. Aplic., Campinas, 43 (2): 203-226, Jul./Dez. 2004

STERNFELD, L. Aprender português-língua estrangeira em ambiente de estudos sobre o Brasil: a produção de um material. Campinas: Unicamp, dissertação de mestrado, 1996.

WIDOWSON, H.G. Teaching language as communication. Oxford: OUP, 1978.

\section{AS AUTORAS}

Anelise Fonseca Dutra, Doutora, UFOP,

E-mail: aneldutra@gmail.com

Sílvia Penna, Mestre, UFOP,

E-mail: silviapenna.efl@gmail.com. 


\section{ANEXO 1}

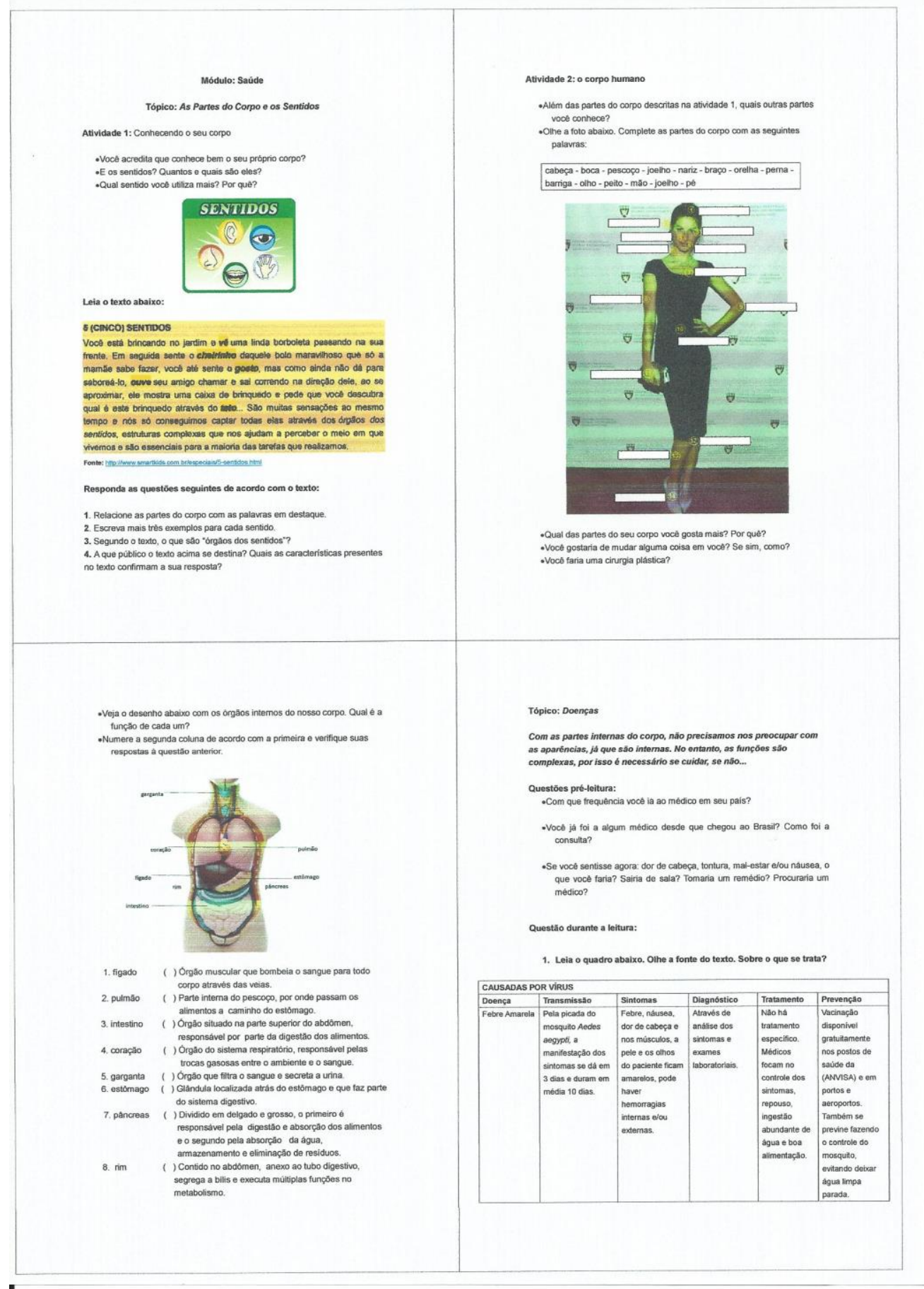




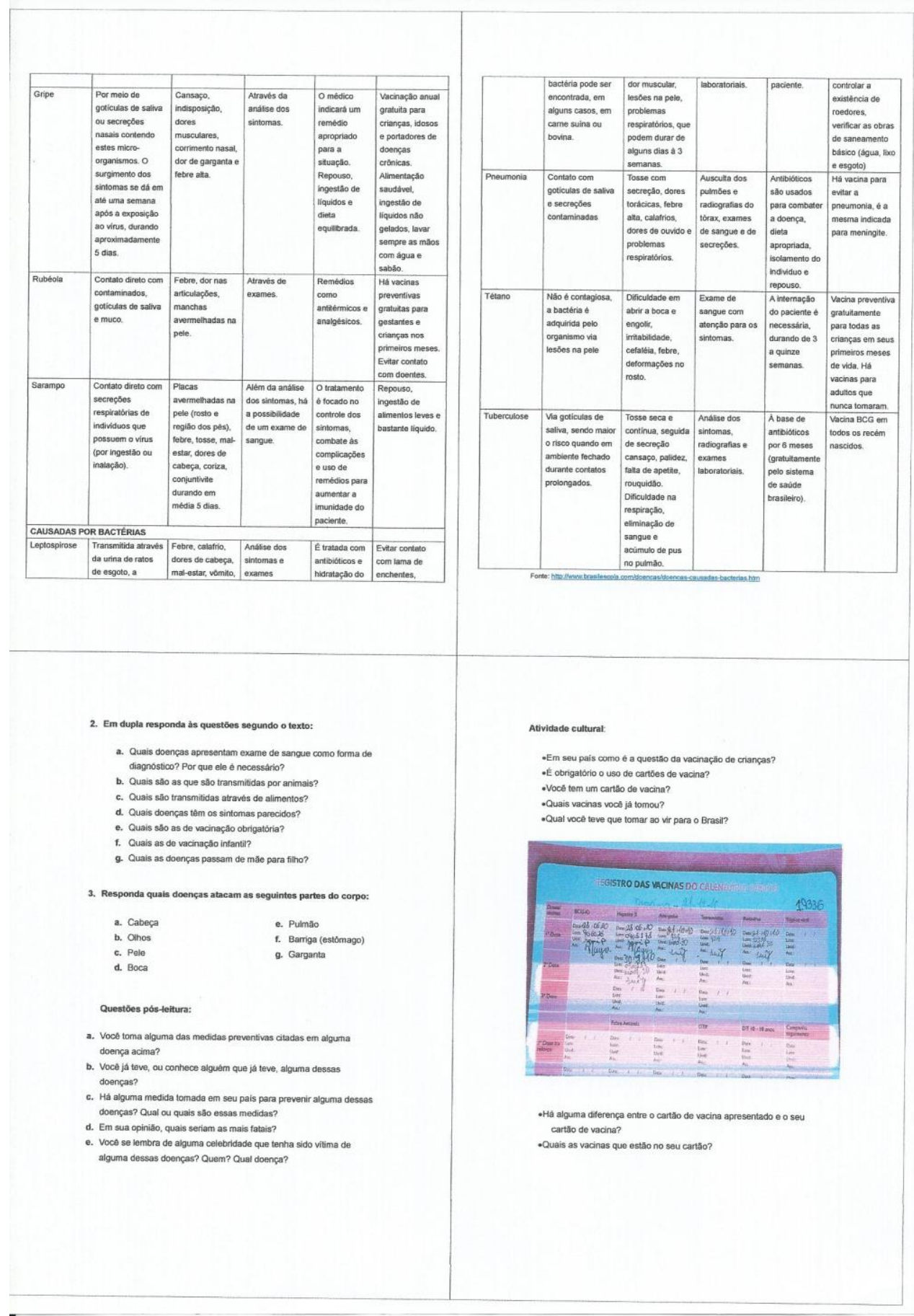




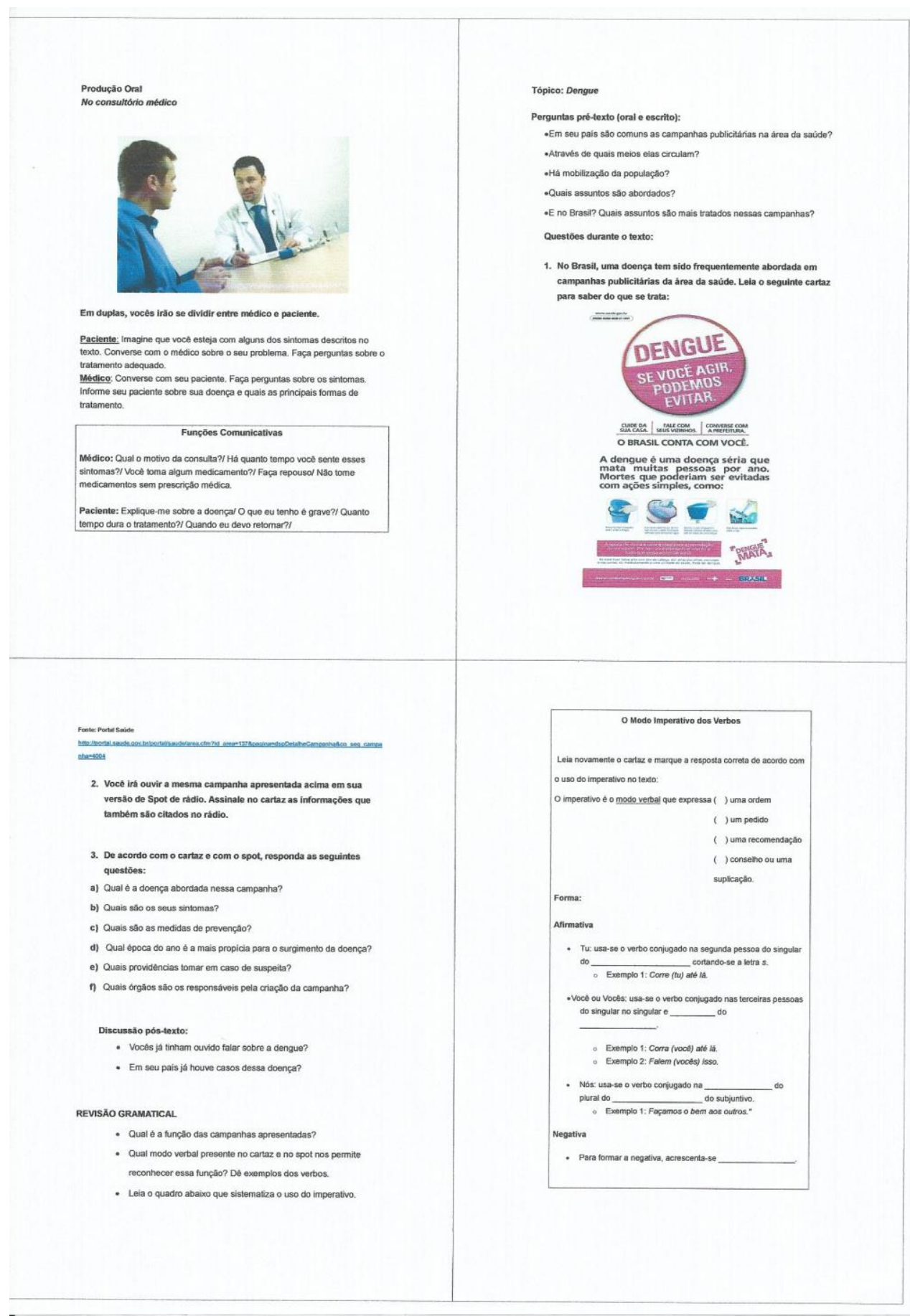


A.F.Dutra; S.Pena/IV SILID III SIMAR 2013 